\title{
FIELD MONITORING AND NUMERICAL ANALYSIS OF THERMAL BEHAVIOR OF LARGE SPAN STEEL STRUCTURES UNDER SOLAR RADIATION
}

\author{
Zhongwei Zhao ${ }^{2}$, Hongbo Liu ${ }^{1,2 *}$ and Zhihua Chen ${ }^{1,2}$ \\ ${ }^{1}$ State Key Laboratory of Hydraulic Engineering Simulation and Safety, Tianjin University, Tianjin 300072, China \\ ${ }^{2}$ School of Civil Engineering, Tianjin University, China \\ *(Corresponding author: E-mail: hbliu@tju.edu.cn)
}

Received: 15 March 2016; Revised: 9 June 2016; Accepted: 13 August 2016

\begin{abstract}
The erection process of large span structures is complex and requires long time to complete, even a few years for some major engineering projects. The structure will expose to solar radiation which will result in larger temperature change in service phase. In order to obtain the temperature distribution and thermal behaviour of large span steel structures under solar radiation, a numerical simulation method based on the ASHRAE model is presented in this paper. In order to provide insights into temperature distribution and data to verify the presented numerical simulation method, field monitoring system was designed for an actual project. The temperature distribution mechanical response of the entire structure was derived by fielding monitoring. Using the temperature numerical simulation method, the temperature distribution and thermal behaviour of a typical steel structure, the lattice shell structures, were studied. The study showed that: 1 ) the daily temperature variation caused by solar radiation has little effect on the components which located at upper part of spatial latticed shell structures, the internal force can be released by deformation. 2) The components connected to supports were sensitive to thermal load. They were in shadow of the upper structures in general, so the temperature caused by solar radiation has smaller effect than effect of seasonal temperature difference. 3) The shell-shaped latticed shell structures behave like arch, and the internal force can be released by deformation.
\end{abstract}

Keywords: Large span steel structures, thermal behavior, solar radiation, field monitoring, numerical analysis

DOI: $10.18057 /$ IJASC.2017.13.3.1

\section{INTRODUCTION}

Steel structures have been popular in recent years. They have many engineering advantages, such as light weight, fast assembly, large span capability and ease to form various attractive geometrical surfaces. Therefore, steel structures are used widely in sport stadiums and gymnasiums, exhibition centers, airport, factory buildings.

The erection process of large span structures is complex and needs long time to complete, even a few years for some major engineering projects. So the structures under-construction will also experience daily and seasonal temperature changes. If the main structure of one building is completed without accessory structures, for example the roof board, the whole structure will exposed to solar radiation and the maximum temperature of the steel structure surface may exceed $60^{\circ} \mathrm{C}$ in summer. In most cases, the thermal load during this erection process is not considered in design process of the structure. And so far few researchers have investigated the effect of this kind of thermal load on mechanical behavior of structures.

In the past decades, most researches have devoted to design approaches and investigation on the structural behavior of steel structures [1-8]. In the design process of steel structures, the structural behavior under the gravity load, dead load, live load, wind load, thermal load, snow load and earthquake action are analyzed. For long span steel structures, the thermal load has a significant effect on its structural behavior. For structures without roof board, more attentions should be paid to the thermal load induced by solar radiation. 
The thermal load of structures without roof board under construction induced by ambient is more non-uniform and higher than the corresponding ambient air temperature due to the solar radiation. Liu [9] divided the structures influenced by solar radiation into three categories. The first type is the steel structures exposed to solar radiation, such as the steel arches and the steel structures under construction is also included. The second type is the steel structures which use glass or ETFE as its roof materials. The third type is the steel structures which use light steel as its roof materials. For the first type steel structures, the solar radiation can radiate on the steel surface directly.

For large-span steel spatial structures, thermal load caused by solar radiation may lead some members to reach ultimate state [10-15]. However, few researches have conducted studies on thermal behavior of spatial structures under construction. This limitation motivates this study on the thermal behavior of steel structures under construction considering solar radiation. Liu [9] put forward a precise numerical simulation method for the temperature distribution induced by solar radiation of large-span steel spatial structures. The method was adopt in this paper to calculate temperature field under solar radiation of an actual project.

\section{ENGINEERING SITUATION}

YUJIAPU Railway Station Building is located in Tianjin, China with a building area of $86200 \mathrm{~m}^{2}$. The three-story building with complex roof shapes has two stories underground. The station hall, including waiting and entrance halls, machine rooms, and an office, are on the first story. The platform that has three island platforms and six arrival-departure tracks are on the second story. Above ground is a shell-shaped single-layer lattice lighting roof. The main members of the whole structure are 72 curved steel box girders that intersect each other, as shown in Figure 1. Figure 2 shows the main steel structures after unloading process, which is $142 \mathrm{~m}$ in length, $80 \mathrm{~m}$ in width, and the vector height is $24 \mathrm{~m}$. A ring beam was set on the top and bottom of the shell to connect and constrain the steel box girders.

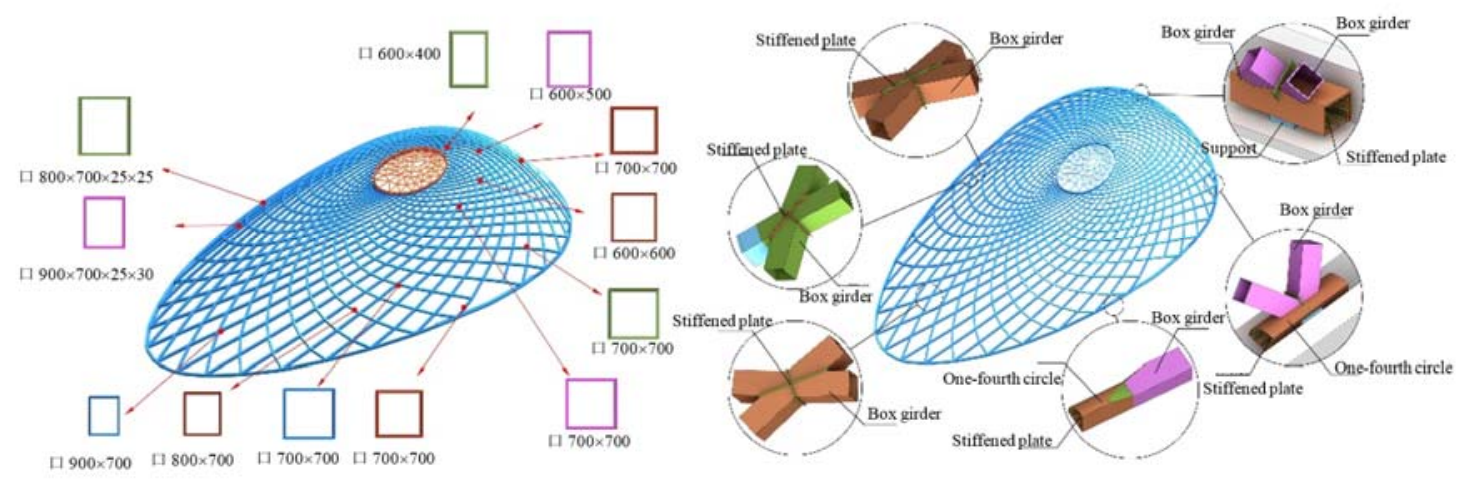

a) Section of box girder(unit: $\mathrm{mm}$ )

b) Nodal style

Figure 1. Section and Node of YUJIAPU Railway Station 


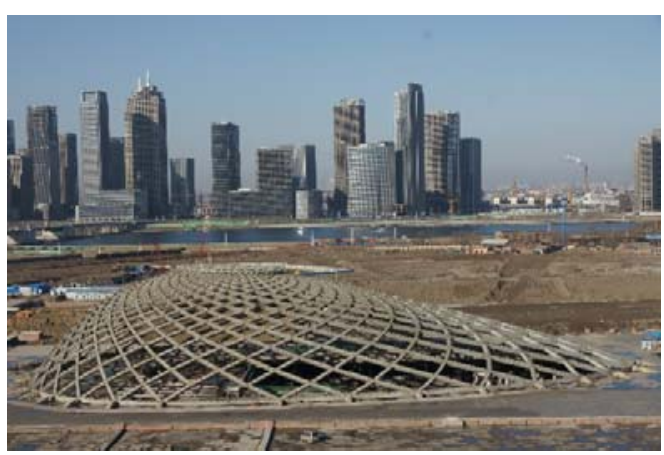

a) Vertical view

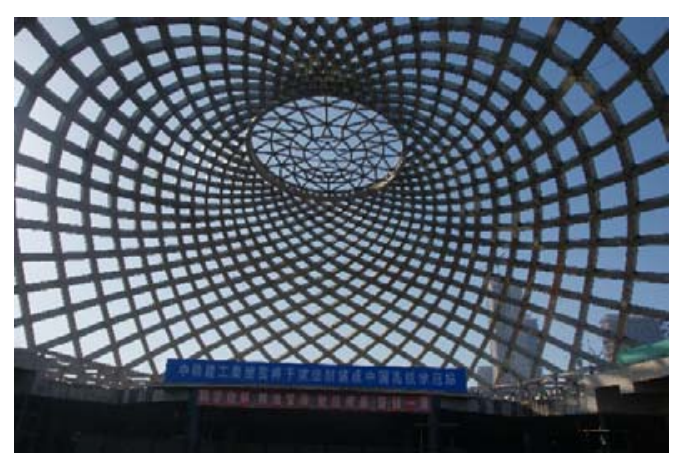

b) Upward view

Figure 2. YUJIAPU Railway Station after Unloading Process

The somatotype of the structure is similar to a shell. The structure is under complex stress, and 10 kinds of nodes, each different from one another, were used. Every component torsion has different angles to keep the configuration smooth. Performing construction simulation on this project is necessary to overcome several construction difficulties.

\section{NUMERICAL SIMULATIONS METHOD}

In 1950s, many researchers had already begun to evaluate the temperature distribution of pavements [16-17], bridges [18-20] and dams [21] considering the solar radiation. In these studies, the one-dimensional or two-dimensional heat conductivity model was adopted in the numerical simulation. However, the temperature distribution of the spatial steel structures cannot be predicted using these numerical methods under solar radiation because of its three-dimension spatial property. Then Liu [9] developed the method for calculating temperature distribution of spatial structures. In this paper, the same method was adopted for calculating temperature field of YUJIAPU railway station building which is during construction phase.

The decisive factors in Liu's [9] method mainly include convection heat, solar radiation and long wave radiation. So the boundary condition of the steel surface can be expressed as Eq. 1 correspondingly. The first term indicates the contribution of convection heat. The second and third term refer the solar radiation and long wave radiation respectively. The thermal properties of steels were acquired from the corresponding codes as listed in Table 1.

$\left.\lambda \frac{\partial T}{\partial n}\right|_{\Gamma}=h\left[T_{a}(t)-T\right]+q_{S}(t)+q_{L}(t)$

Where $h$ is heat convection coefficient $\left(w / m^{20} C\right)$ and it can be calculated by the method presented by Yazdanian and Klems ${ }^{[22]} ; T_{a}$ is ambient air temperature.

Table 1. Thermal Properties of Steel

\begin{tabular}{|c|c|c|c|}
\hline properties & $\begin{array}{c}\text { density } \\
\mathrm{kg} / \mathrm{m}^{3}\end{array}$ & $\begin{array}{c}\text { Heat conduction coefficient } \\
\mathrm{J} /\left(\mathrm{m} \cdot \mathrm{s} \cdot{ }^{0} \mathrm{C}\right)\end{array}$ & $\begin{array}{c}\text { Specific heat } \\
\mathrm{J} /\left(\mathrm{kg} \cdot{ }^{0} \mathrm{C}\right)\end{array}$ \\
\hline value & 7850 & 56 & 480 \\
\hline
\end{tabular}


The ASHRAE clear-sky model was adopted for calculation of solar radiation. In this model, the total global solar radiation is assumed to be the sum of direct radiation, diffuse radiation, and the solar radiation reflected from the surrounding surface ${ }^{[21]}$, as shown in Eq. 2.

$q_{s}=\varepsilon\left(G_{D}+G_{d}+G_{R}\right)$

Where $\varepsilon$ is the solar absorption coefficient, $G_{D}$ is the direct radiation, $G_{d}$ is the diffuse radiation and $G_{R}$ is the solar radiation reflected from the surrounding surface. The detailed computational method of each item can be found in [9].

The Stefan-Boltzmann equation was used for calculation of long wave radiation, shown as Eq.3.

$q_{l}=\varepsilon_{f} \sigma\left(F_{w g}\left(T_{g}^{4}-T^{4}\right)+F_{w s}\left(T_{s k y}^{4}-T^{4}\right)\right)$

Where $\varepsilon_{f}$ is the ratio of the radiation emitted by a surface; $\sigma$ is Stefan-Boltzmann constant $=5.67 \times 10^{-8} \mathrm{~W} /\left(\mathrm{m}^{2} \cdot \mathrm{K}^{4}\right) ; T_{\text {sky }}$ is the effective temperature of sky, usually calculated by $T_{a}-6 ; T_{g}$ is the ground temperature.

In addition, the ambient temperature and wind speed are critical parameters affecting the steel temperature, because the convection heat transfer between steel surface and air is determined by the ambient temperature and the long wave radiation irradiating on steel surface. In this paper, the air temperature data for the monitoring site were used as shown in Figure 3.

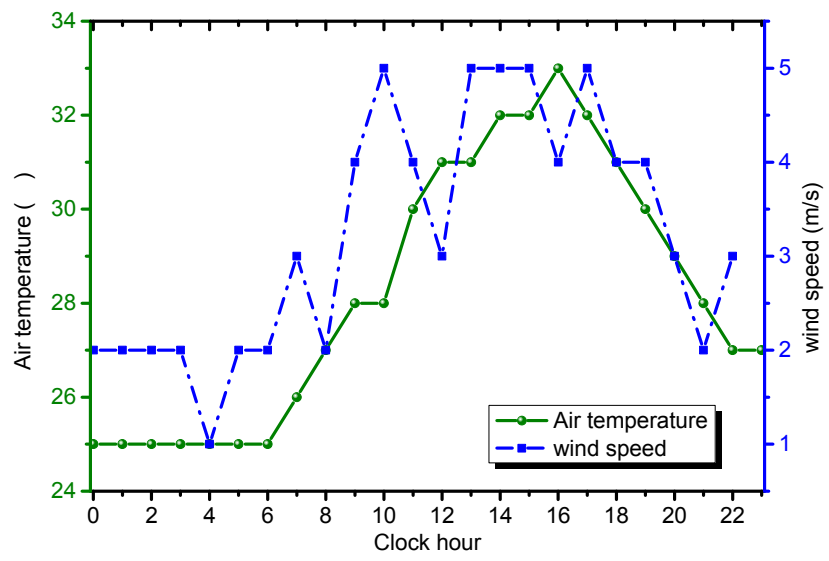

Figure 3 Monitored air temperature and wind speed on August 1, 2014

\section{FIELD MONITORING SYSTEM}

A temperature and stress monitoring system devised for the Yujiapu railway station building was installed in July, 2014 and has been operated since then. There were 44 temperature sensors and 22 strain gages were used, and 4 temperature sensors and 2 strain gages for each components. Distribution of monitoring components was shown as in Figure 4. 


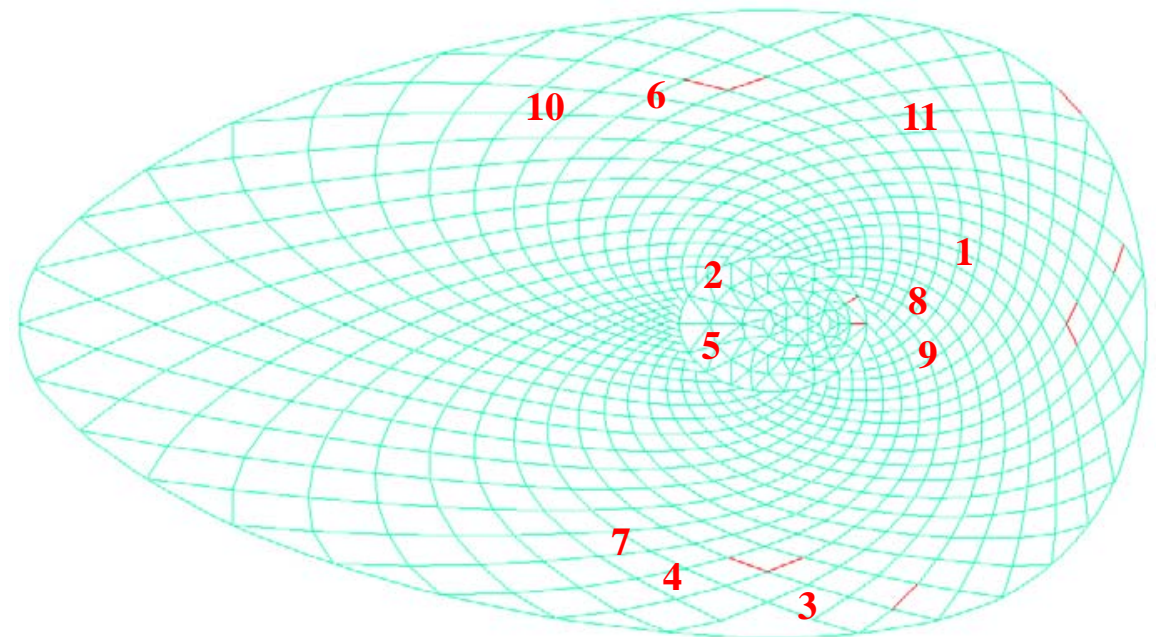

Figure 4. Distribution of Monitoring Components

Figure 5. showed installation form of monitoring sensors on each component in detail. Four temperature sensors and two stress sensors were installed on middle part of each component. Temperature sensors were installed on each side of the component and stress sensors were installed on top and bottom of the components. The section of component located at skylight is circle and the others are rectangular section. Figure 6 shows actual structure under solar radiation and monitoring sensors on each component.

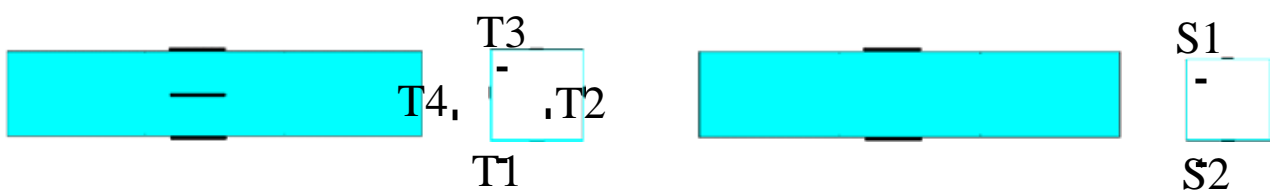

a) Rectangular section

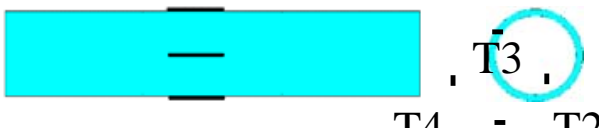

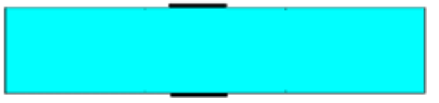

b) Circular section

\section{T1}

Figure 5. Positions of Temperature Sensors and Strain Gauges

Notation: T-temperature S-stress

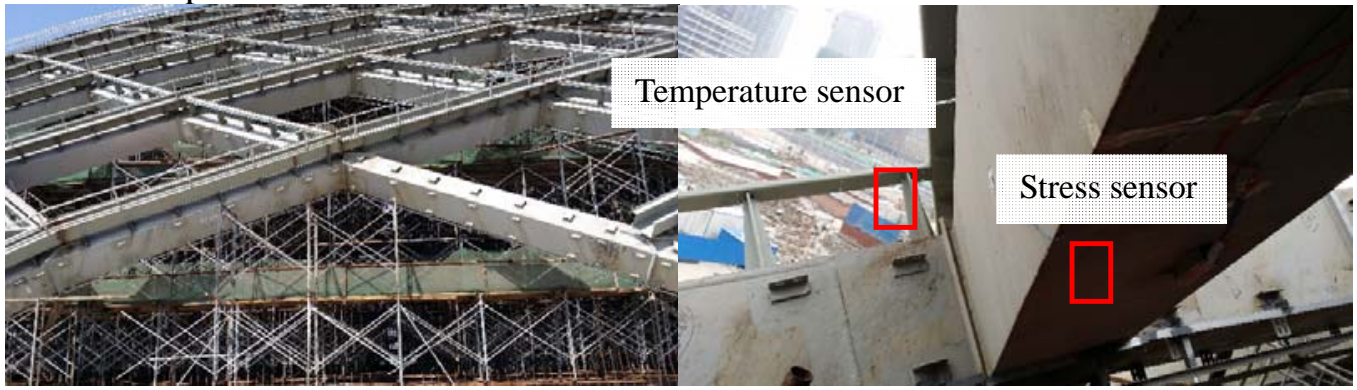

a) Solar radiation

b) Monitoring component 


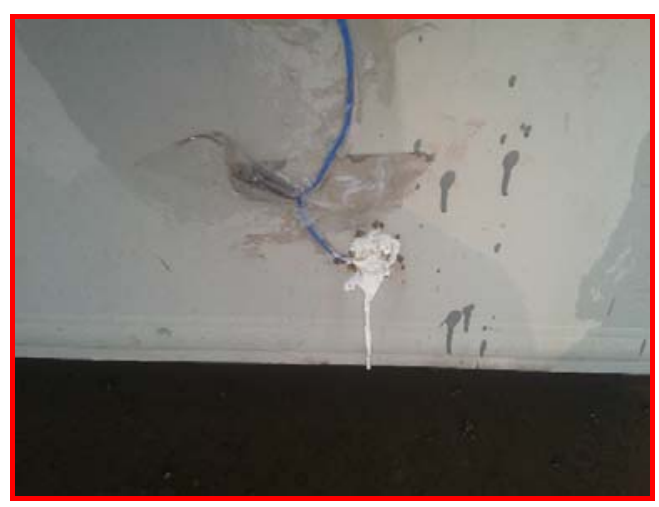

c) Temperature sensor

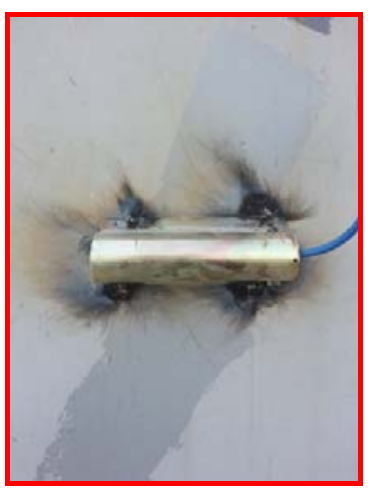

d) Stress sensor

Figure 6. Installation of Temperature Sensor and Stress Sensor

\section{RESULTS AND DISCUSSIONS}

\subsection{Uniform Temperature Field under Solar Radiation}

The field temperature was collected per 15 minutes. The temperature-time curves of each monitoring component on $1^{\text {th }}$ August are shown in Figure 7 Figure 17. The results derived by field monitoring and numerical analysis were compared with each other. In numerical analysis, the maximum and minimum temperature of monitoring components was extracted and the field air temperature and wind speed were taken in account.

It can be seen from the curves of monitoring temperature that some monitoring point present a sawtooth shape, that is caused by shadow effect among components. The monitoring component will be in shadow caused by other components from time to time. The maximum temperature happened at component 2 which is located at skylight of the structure.

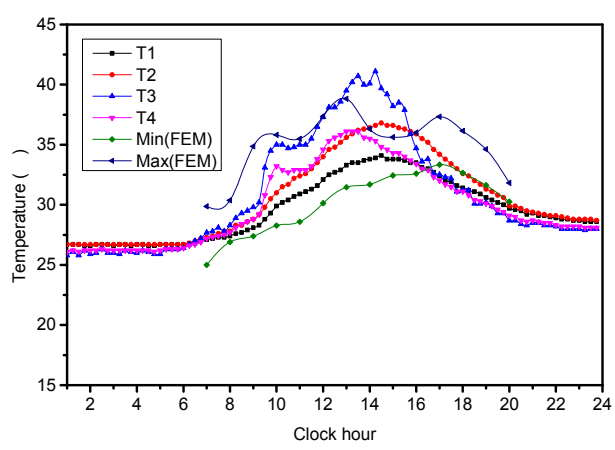

Figure 7. The Temperature-time Curve for Component 1

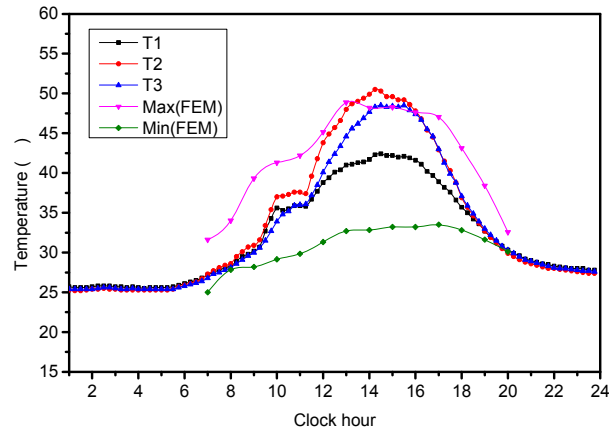

Figure 8. The Temperature-time Curve for Component 2 


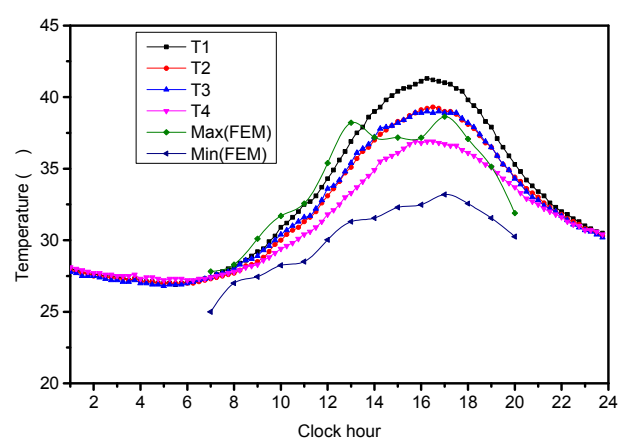

Figure 9. The Temperature-time Curve for Component 3

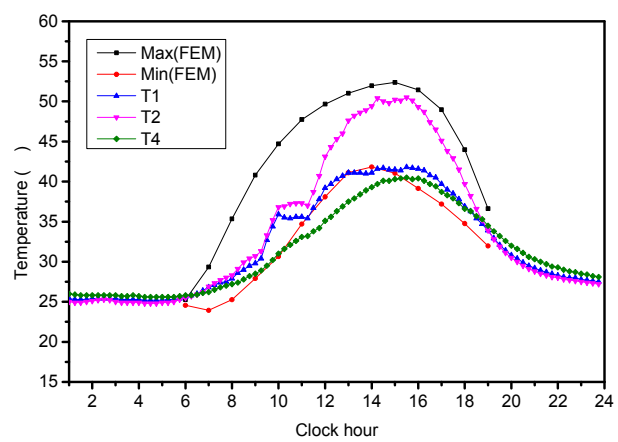

Figure 11. The Temperature-time Curve for Component 5

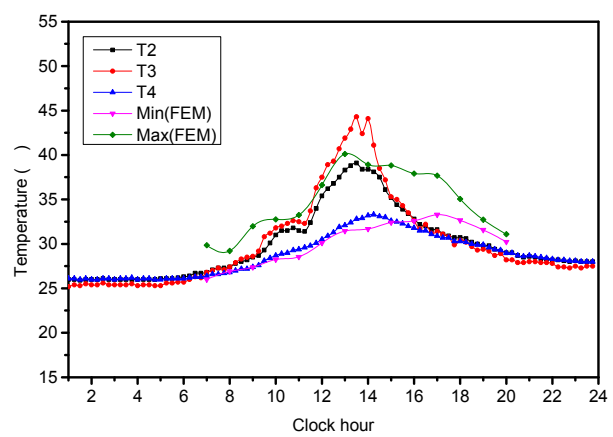

Figure 13. The Temperature-time Curve for Component 7

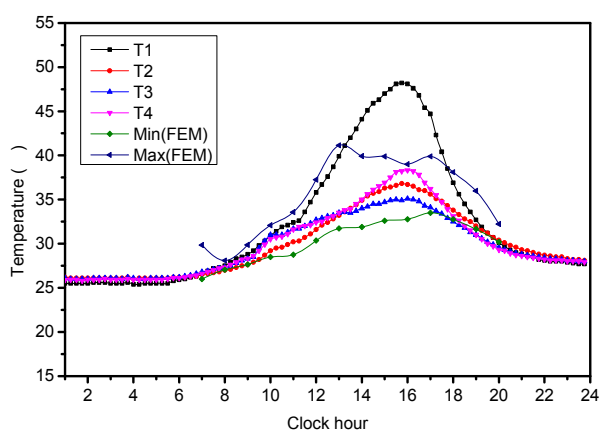

Figure 15. The Temperature-time Curve for Component 9

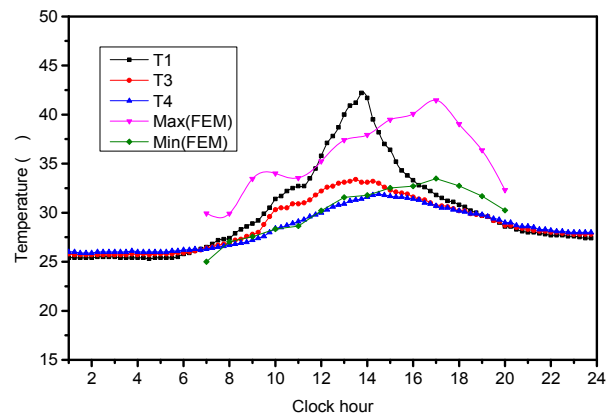

Figure 10. The Temperature-time Curve for Component 4

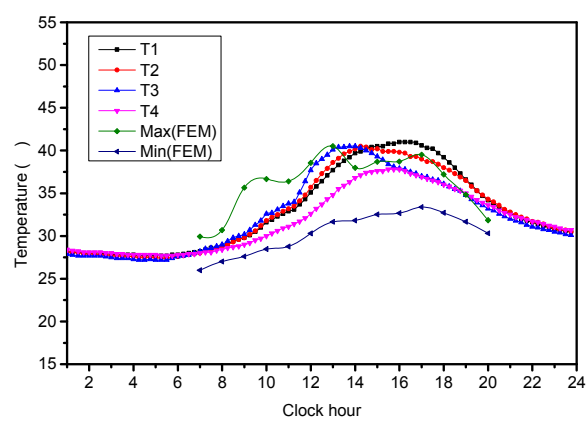

Figure 12. The Temperature-time Curve for Component 6

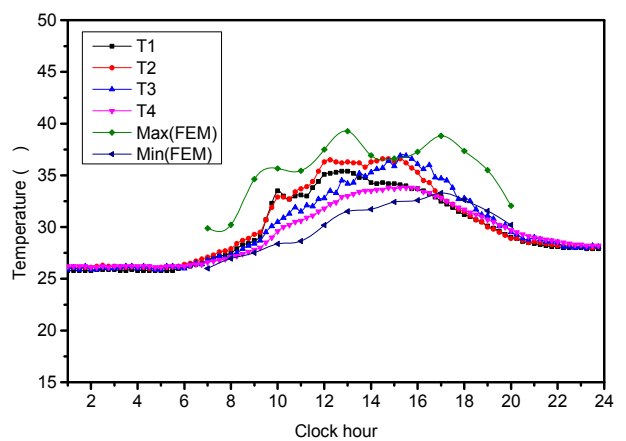

Figure 14. The Temperature-time Curve for Component 8

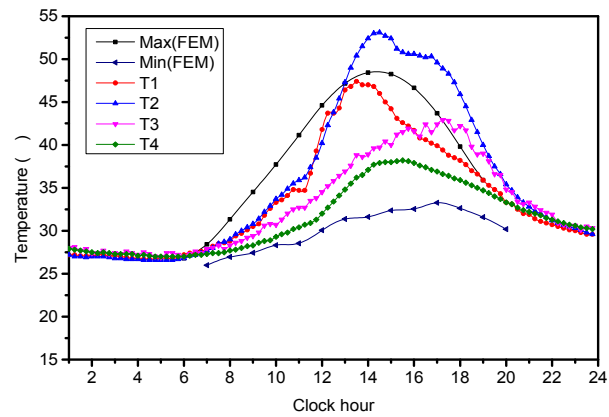

Figure 16. The Temperature-time Curve for Component 10 


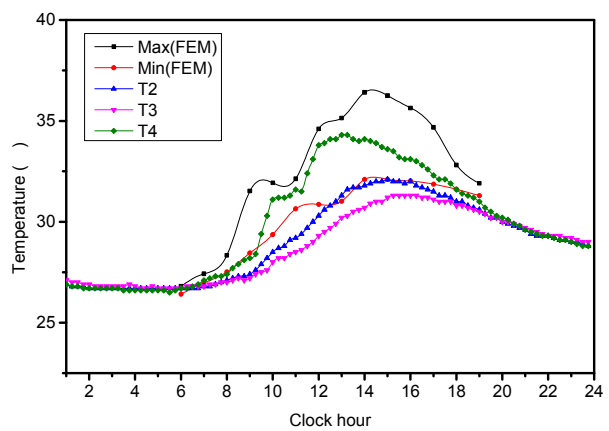

Figure 17. The Temperature-time

Curve for Component 11

Table 2. Temperature of 11 Components

\begin{tabular}{|c|c|c|c|c|c|c|}
\hline NUM & CM1 & CM2 & CM3 & CM4 & CM5 & CM6 \\
\hline Temperature from monitoring & 40.7 & 50.5 & 41.3 & 42.2 & 50.5 & 41 \\
\hline Temperature from FEM analysis & 38.8 & 48.8 & 38.2 & 41.45 & 52.3 & 40.51 \\
\hline Error1 & 0.046 & 0.033 & 0.075 & 0.017 & 0.035 & 0.011 \\
\hline NUM & CM7 & CM8 & CM9 & CM10 & CM11 & \\
\hline Temperature from monitoring & 44.1 & 36.5 & 48.2 & 53.1 & 32 & \\
\hline Temperature from FEM analysis & 40.12 & 39.2 & 41.1 & 48.4 & 36.4 & \\
\hline Error & 0.090 & 0.073 & 0.147 & 0.088 & 0.13 & \\
\hline
\end{tabular}

It is clear that the temperature value obtained by numerical analysis was generally consistent with the monitoring results, with a maximum difference of $14.7 \%$.

Reasons attributing to the discrepancies might be due to variance in the solar radiation model, variance in solar radiation absorption and ground reflectance, wind speed at each component, etc. As the complexity of the algorithm, the shadow effect among components was not taken into account which is the main cause of difference between temperature derived by FEM method and field monitoring.

\subsection{Stress Caused by Non-uniform Temperature}

The finite element model of the structure constitutes of beam element and Beam 188 in ANSYS was adopted, support at the bottom of the structure was constraint in radial and vertical direction. The temperature field of the whole structure was obtained in above section, it was applied as beam thermal load, shown as in Figure 18. 


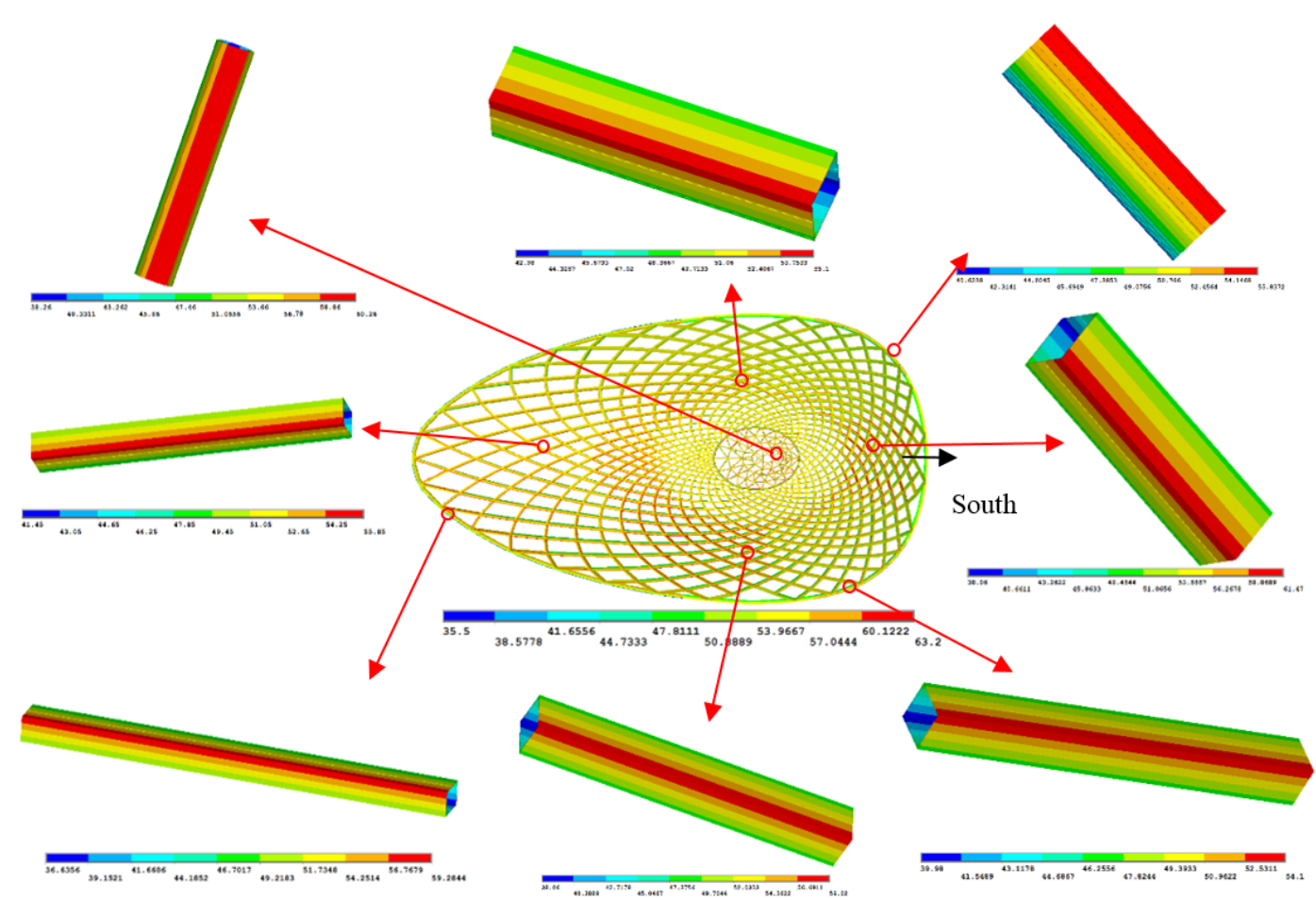

Figure 18. Contour of Temperature Field under Solar Radiation at 12 o'clock

Temperature at different clock hour was input as thermal load to get the stress variation along with temperature. The stress-time curves of components were shown in Figure 19 Figure 29. It can be concluded that the results obtained by FEM method agree well with that obtained by field monitoring.

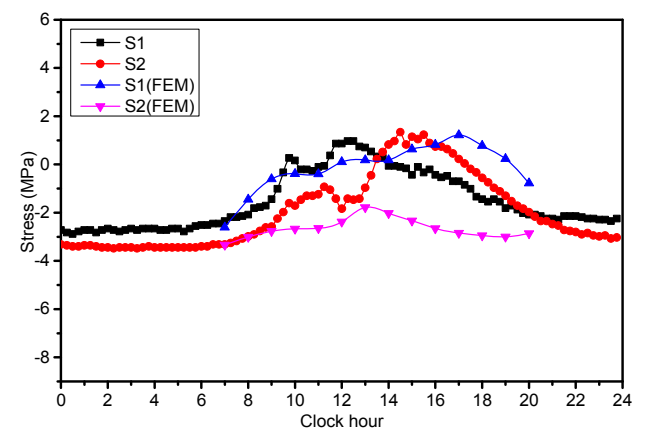

Figure 19. The Stress-time Curve for Component 1

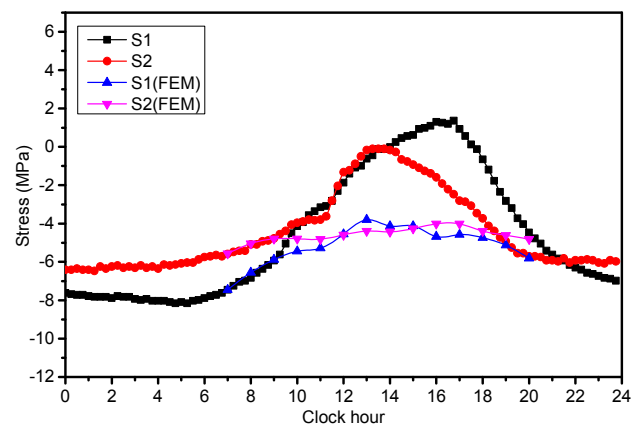

Figure 21. The Stress-time Curve for Component 3

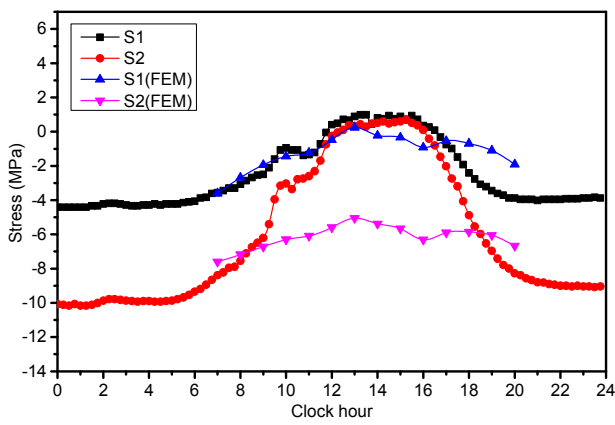

Figure 20. The Stress-time Curve for Component 2

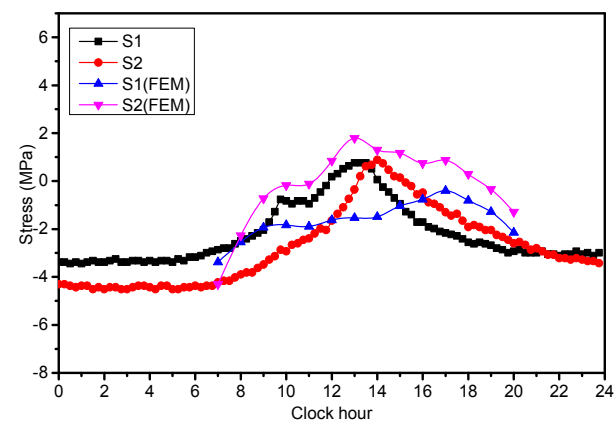

Figure 22. The Stress-time Curve for Component 4 


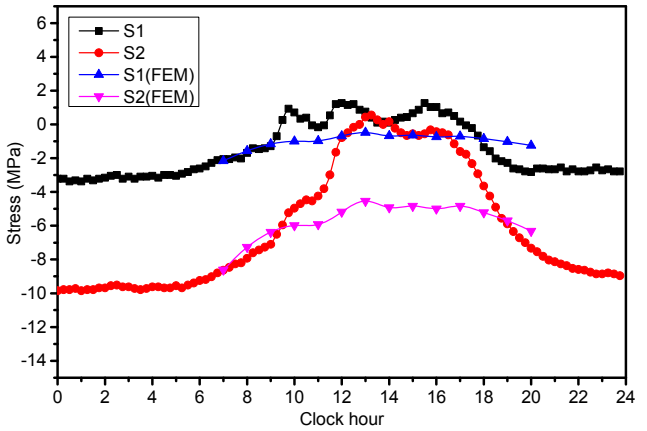

Figure 23. The Stress-time Curve for Component 5

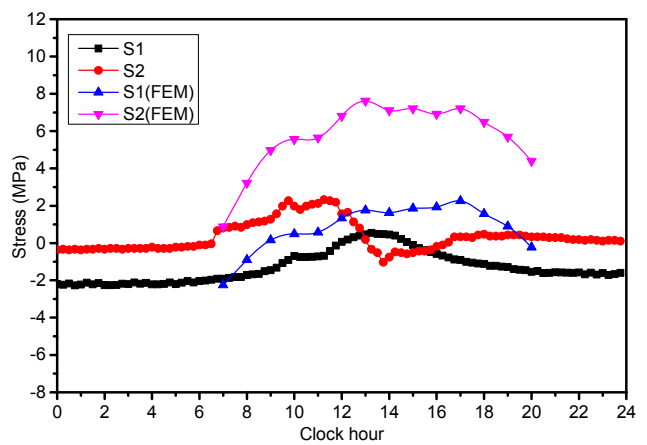

Figure 25. The Stress-time Curve for Component 7

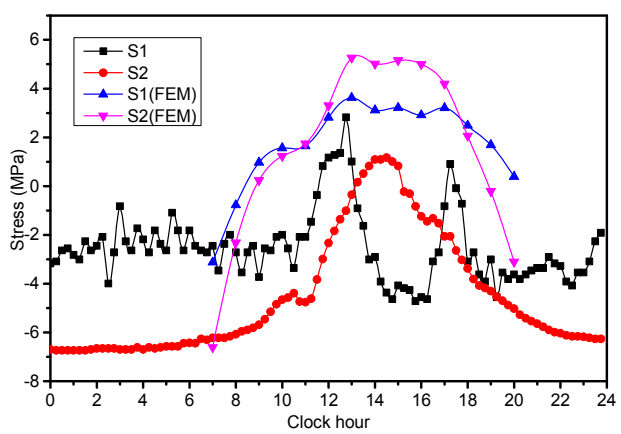

Figure 27. The Stress-time Curve for Component 9

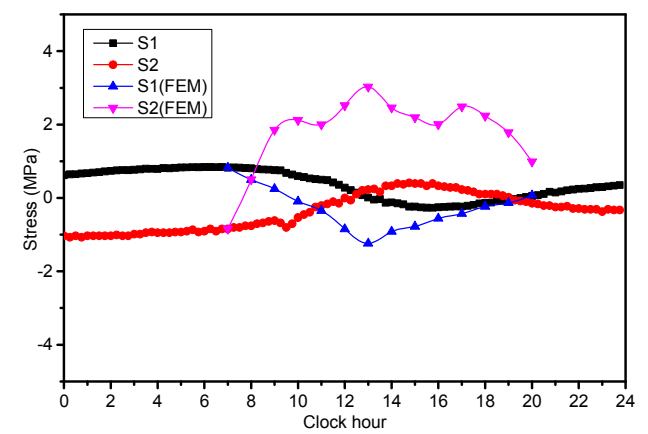

Figure 29. The Stress-time Curve for Component 11

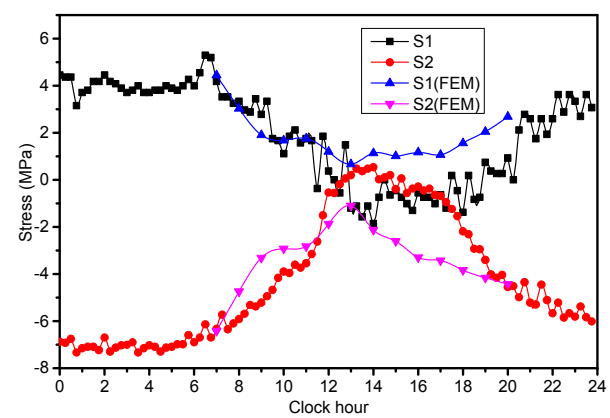

Figure 24. The Stress-time Curve for Component 6

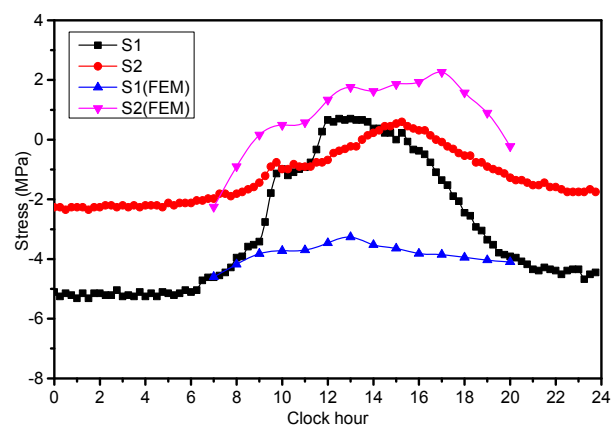

Figure 26. The Stress-time Curve for Component 8

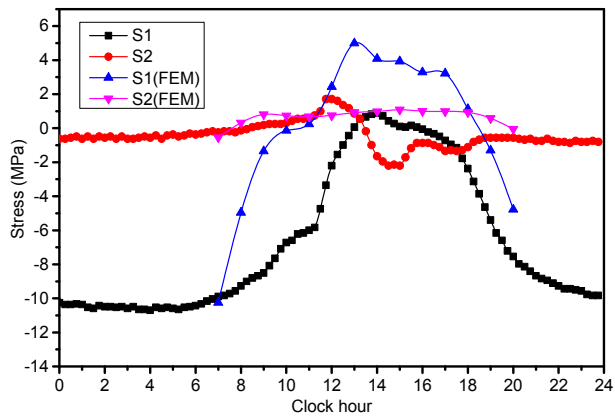

Figure 28. The Stress-time Curve for Component 10 
Although correlated well with changing trends of stress obtained from field monitoring, FE simulations again predict smaller values of stress changing. However, as the stress changing is very small in value, it is difficult to accurately quantify monitoring value. It can be seen from comparison that there is larger errors existing at individual monitoring points. The difference between calculated temperature field and actual condition is the main cause of difference between stress computed and monitored. Due to exact temperature field of each component cannot be obtained by field monitoring method, the temperature field derived by FEM method was adopted. Beam element whose temperature field can only change linearly along axis was adopted in numerical model, this determined there must be errors between simulated temperature field and actual condition. At the same time, the construction error, the construction load, etc., are all responsible for the computed errors. The results derived by numerical analysis relatively precise due to influence of error in solar radiation, wind speed and shadow effect, etc.. After all, the maximum deviation for stress is less than $10 \mathrm{MPa}$.

To investigate the influence of the thermal load on deformation of the structure, nodal displacement at typical location, shown as in Figure 30, was extracted. Curves of displacement-time were shown as in Figure 31. It can be concluded that nodal displacement at node 2 and node 4 is large than that at node 5. Similarly, nodal displacement at node 1 and node 3 is large than that at node 5 . This present a mechanical behaviour like arch, which is shown in Figure 32, wether in length or short direction.

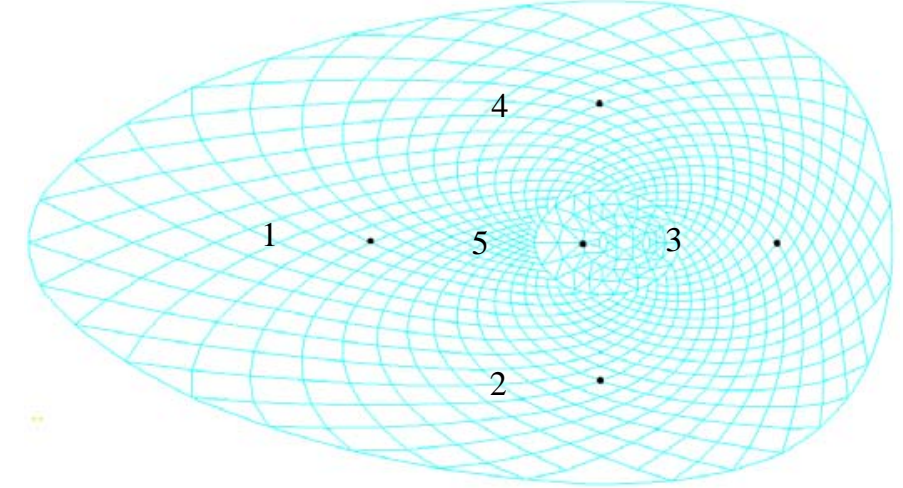

Figure 30. Distribution of Typical Nodes

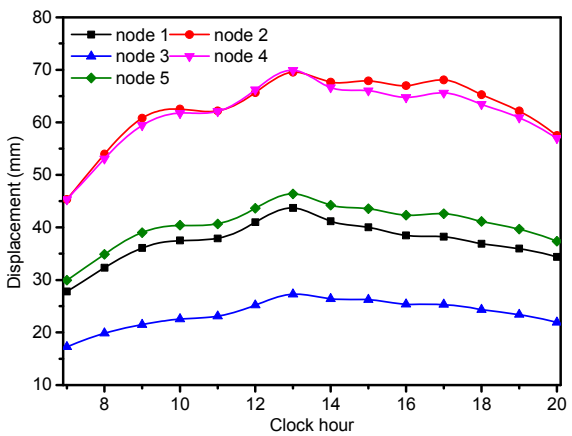

Figure 31. Displacement Curve at Typical Nodes

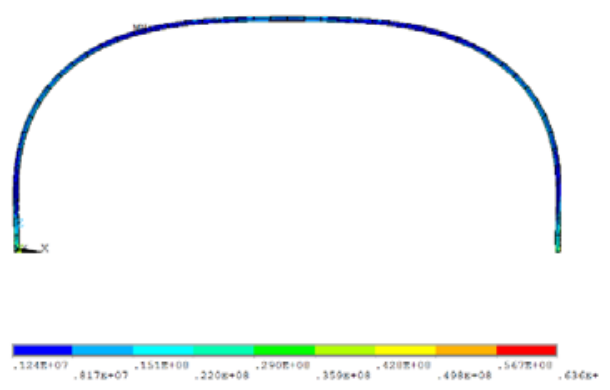

Figure 32. Deformation of Arch in Positive Temperature Difference Conditions

To investigate mechanical behaviour of arch to thermal load, an arch with different vector height and $80 \mathrm{~m}$ in span direction was studied. Arches with rigid connected arch foot and pinned connected arch foot were investigated in this subsection. Figure 33 shows the curves of maximum stress versus vector height at different thermal load. Figure 34 shows that of the pinned arch. 
It can be concluded through comparison of maximum stress in different conditions that the arch with rigid connected foot is more sensitive to thermal load. Thermal load will not influence thermal stress of pinned arch when vector height is larger than $20 \mathrm{~m}$. Similarly, vector height will have a slight influence on thermal stress of rigid arch. The maximum stress happens at arch foot in all cases. The arch with small vector height is more sensitive to thermal load and the rigid arch is more sensitive to thermal load than pinned arch, almost two times.

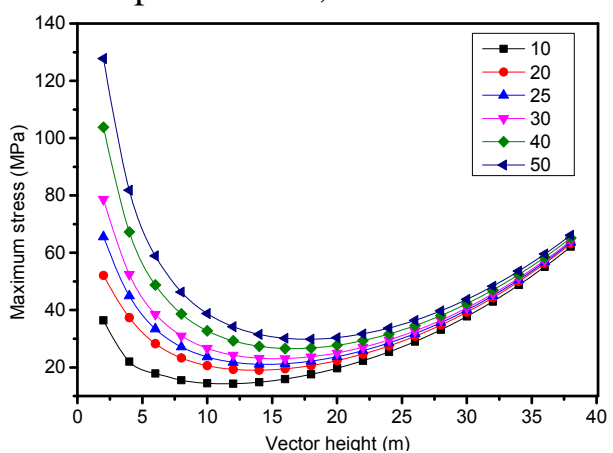

a) Positive thermal load

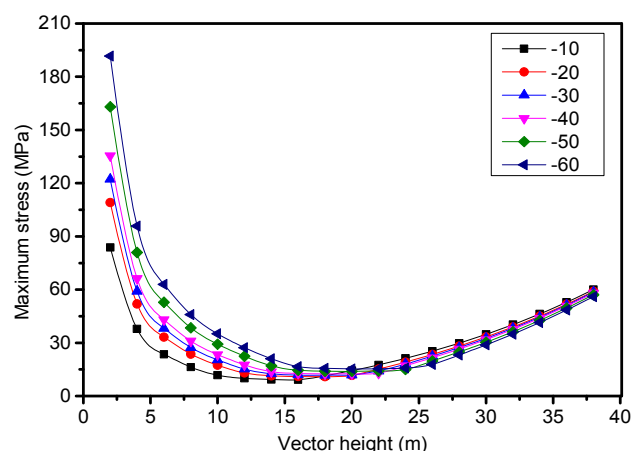

b) Negative thermal load

Figure 33 Rigid arch

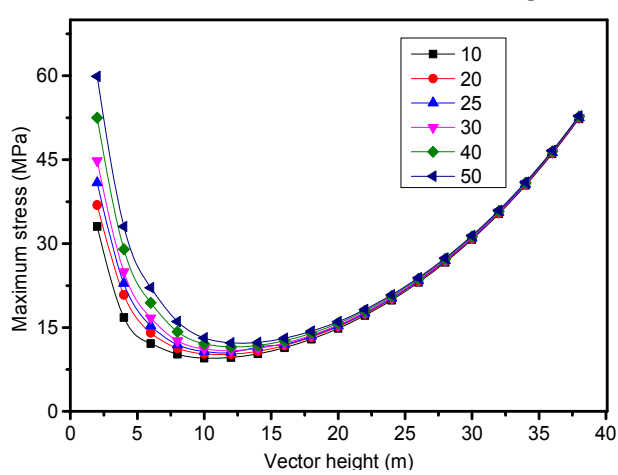

a) Positive thermal load

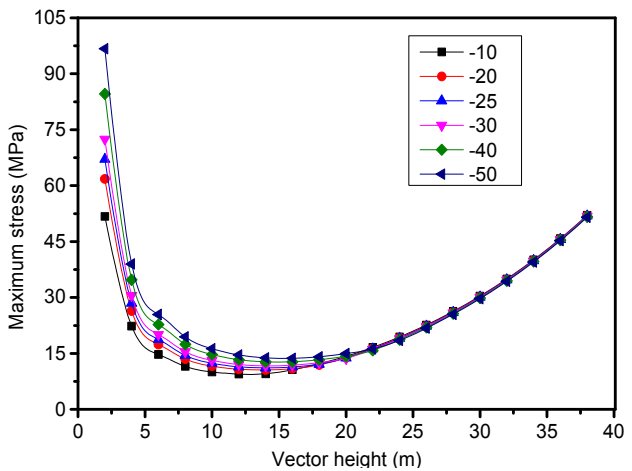

b) Negative thermal load

Figure 34. Pinned Arch

\subsection{Monitoring Results of Stress in Different Months}

To investigate the role seasonal temperature difference playing in the changing of stress. The monitoring results of stress in different months were compared. Due to limited space, monitoring results of component 1 were listed as below, shown as in Figure 35.

It can be concluded that change value of stress caused by seasonal temperature variation is commensurate to that caused by daily temperature variation. Similar to that daily temperature caused by solar radiation, seasonal temperature difference will also not cause big changes in stress for components of upper lattice shell. The change magnitude of stress in summer is large than that in winter for the solar radiation in summer is intensive than that in winter. The change value of stress caused by solar radiation may even larger than that caused by seasonal temperature difference. Figure 36 shows the changing history of stress of component 11 . It can be concluded that as the influence of shadow effect, solar radiation will also not induce big change in stress of components which located at bottom of the entire structure. At the same time, installation of the bottom girder was done in summer, the enclosed structure is not sensitive to negative temperature difference. 


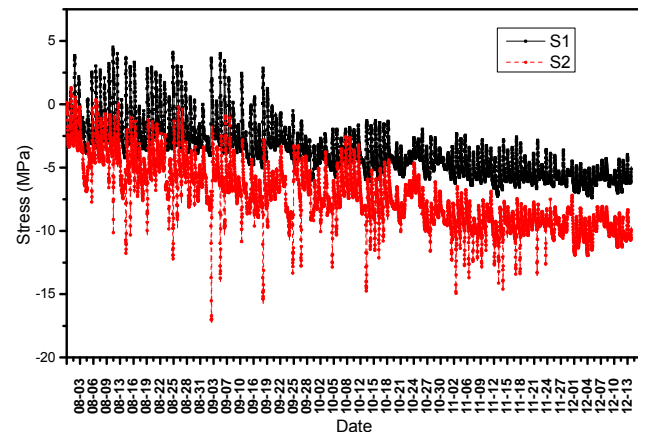

Figure 35. Time History of Monitoring Results for Component 1

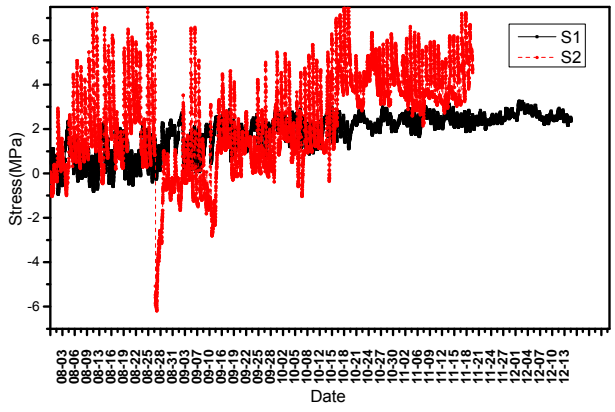

Figure 36. Time History of Monitoring Results for Component 11

\subsection{Thermal Behavior of the Entire Structure}

To investigate the influence of temperature difference on different parts of the structure, the entire structure was divided into three parts according to characteristic of the entire structure. That is the bottom girder (BG), the upper lattice shell (ULS) and the upper girder (UG), shown as in Figure 37.

The healing temperature was $14 \pm 5^{\circ} \mathrm{C}$ according in actual construction process. The temperature field under solar radiation on $22^{\text {th }}$ July, 2014, and $22^{\text {th }}$ December, 2014, was obtained by conducting numerical analysis. The changing curves of maximum stress of different parts of the whole structure was obtained by applying thermal load.

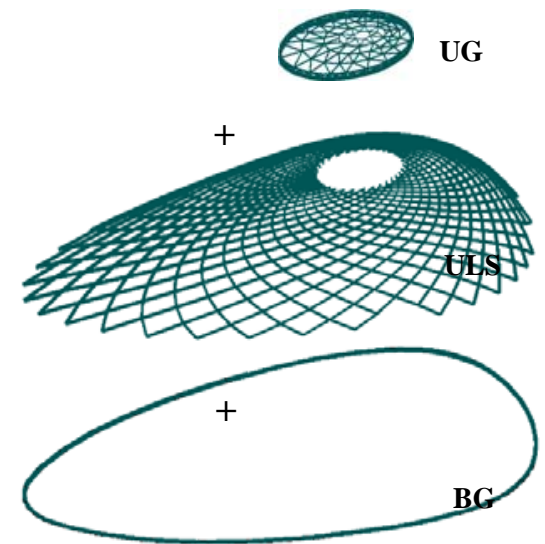

Figure 37. Constitution of the Whole Structure

The changing curves of maximum stress (only under the influence of thermal load) of different parts were shown as in Figure 38 .It can be concluded from Figure 38 a) that the changing value of ULS, BG and UG are 11.9MPa, 13.1MPa and 22.15MPa, respectively, in summer. The maximum stress of BG is $86.5 \mathrm{MPa}$ and is much larger than the other two parts which is $48.7 \mathrm{MPa}$ and $60.2 \mathrm{MPa}$, respectively. This indicates the UG is much sensitive to positive thermal load and the ULS is the least sensitive compared to other two parts.

The temperature field on $22^{\text {th }}$ December was also applied and the reference temperature in ANSYS software package was changed to simulate ambient temperature. The changing curves of maximum stress is shown as in Figure $38 \mathrm{~b}$ ). It can also be concluded that the changing value of ULS, BG and $\mathrm{UG}$ are $4.6 \mathrm{MPa}$, 11.4MPa and 3.4MPa, respectively. The maximum stress of $\mathrm{BG}$ is $114.2 \mathrm{MPa}$ and is much larger than the other two parts which is $37.8 \mathrm{MPa}$ and $28 \mathrm{MPa}$, respectively. It is similar to that 
mentioned before, the UG is much sensitive to negative thermal load and the ULS is the least sensitive compared to other two parts.

The maximum stress of lattice shell, bottom girder and upper girder under gravity are 85.2MPa, 48.4MPa and 94.6MPa, respectively. So the thermal stress takes significant proportion compared to stress cause by gravity, about 57\%, 237\% and 63.4\% for ULS, BG and UG, respectively.

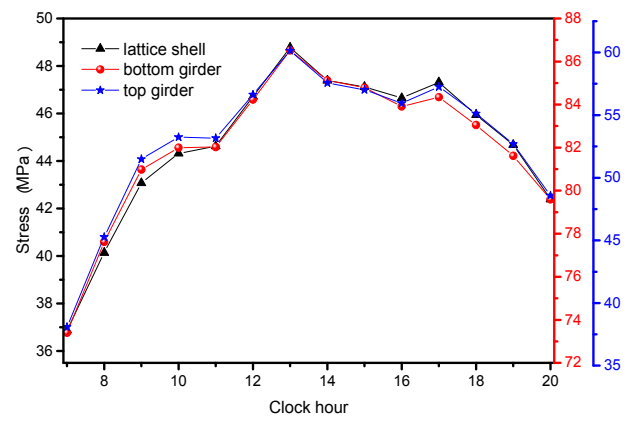

a) Summer

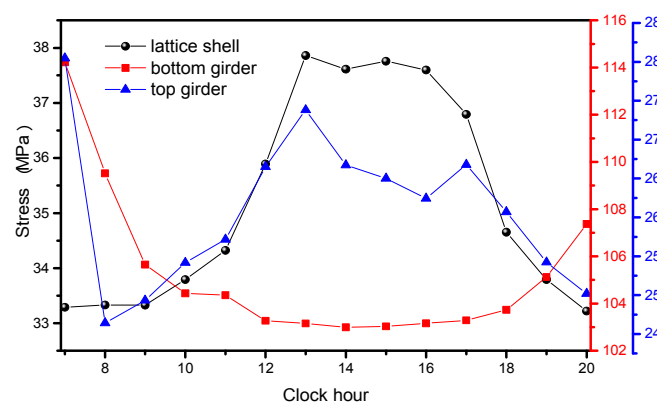

b) Winter

Figure 38. Changing Curves of Maximum Stress of Each Part

From what has been discussed above, it can be concluded that the ULS is not sensitive to daily temperature variation caused by solar radiation, and the planar closed structure, for example the BG and UG is sensitive to temperature variation caused by solar radiation in summer. But the BG is always in the shadow of the upper structures, so the daily temperature variation would have no significant effect on it.

\section{CONCLUSIONS}

1) A numerical model, based on a transient thermal FE analysis, was presented. The temperature field of the whole structure was obtained and accuracy of the result was verified by the monitoring data. The results derived by numerical analysis are relatively precise due to influence of error in solar radiation, wind speed and shadow effect, etc.. After all, the maximum deviation for stress is less than $10 \mathrm{MPa}$.

2) Stress of monitoring point was derived by applying thermal load obtained by method presented in this paper. Results were compared with that field monitoring data. It was concluded that the influence of daily variation of temperature caused by solar radiation on component of steel latticed shell is not significant.

3) Shadow effect among components will cause difference between results obtained by FEM method, but the results is conservative for structural design process.

4) Different parts of the structure has different sensitivity to thermal load. The bottom girder (BG) is most sensitive to seasonal thermal load. The thermal load caused by solar radiation has little influence on it due to shadow effect of the upper structure. 


\section{ACKNOWLEDGEMENTS}

This work was supported by the National Science Foundation of Tianjin (No. 16JCQNJC07100).

\section{REFERENCES}

[1] Alinia, M.M. and Kashizadeh, S., "Effect of Flexibility of Substructures upon Thermal Behaviour of Spherical Double Layer Space Truss Domes, Part I: Uniform Thermal Loading”, Journal of Constructional Steel Research, 2006, Vol. 62, No. 4, pp. 359-368.

[2] Alinia, M.M. and Kashizadeh, S., "Effect of Flexibility of Substructures upon Thermal Behaviour of Spherical Double Layer Space Truss Domes, Part II: Gradient \& Partial Loading”, Journal of Constructional Steel Research, 2006, Vol. 62, No. 7, pp. 675-681.

[3] Alinia, M.M. and Kashizadeh, S., "Effects of Support Positioning on the Thermal Behaviour of Double Layer Space Truss Domes”, Journal of Constructional Steel Research, 2007, Vol. 63, No. 3, pp. 375-382.

[4] Yong, D., “A Practical Approach for Fire Risitance Design of Large Space Building Grid Structures [D]”, Shanghai, Tongji University, 2007.

[5] Liu, H.B., Chen, Z.H. and Zhou, T., "Research on the Process of Pre-Stressing Construction of Suspen-Dome Considering Temperature Effect”, J. Advances in Structural Engineering, 2012, Vol. 15, No. 3, pp. 489-493.

[6] Liu, H.B., Chen, Z.H. and Zhou, T., "Numerical and Experimental Investigation on the Temperature Distribution of Steel Tubes under Solar Radiation”, J. Structural Engineering and Mechanics, 2012, Vol. 43, No. 6, pp. 725-737.

[7] Liu, H.B., Chen, Z.H. and Zhou, T., "Theoretical and Experimental Study on the Temperature Distribution of H-shaped Steel Members under Solar Radiation”, J. Applied Thermal Engineering, 2012, Vol. 37, pp. 329-335.

[8] Liu, H.B. and Chen, Z.H., "Non-Uniform Thermal Behaviour of Suspen-Domewith Stacked Arch Structures”, J. Advances in Structural Engineering, 2013, Vol. 16, No. 6, pp. 1001-1009.

[9] Liu, H.B., Chen, Z.H. and Zhou, T., "Investigation on Temperature Distribution and Thermal Behavior of Large Span Steel Structures Considering Solar Radiation”, J. Advanced Steel Construction, 2013, Vol. 9, No. 1, pp. 41-58.

[10] Li, G.Q. and Zhang, C., “Thermal Response to Fire of Uniformly Insulated Steel Members: Background and Verification of the Formulation Recommended by Chinese Code CECS200, Advanced Steel Construction, 2010, Vol. 6, No. 2, pp. 788-802.

[11] Fan, Z., Wang, Z. and Tian, J., "Analysis on Temperature Field and Determination of Temperature upon Healing of Large-span Steel Structure of the National Stadium”, Journal of Building Structures, 2007, Vol. 28, No. 2, pp. 32-40. (in Chinese)

[12] Pei, Y.Z., Bai, Y., Shi, Y.J., Zhu, D. and Wang, Y.Q., "Temperature Distribution in a Long-span Aircraft Hanger [J], Tsinghua Science and Technology, 2008, Vol. 13, No. 2, pp. 184-190.

[13] Xiao, J.C., Xu, H., Liu, J.K. and Ma, K.J., "The Influence of Intense Solar Radiation on Long-span Spatial Steel Structures [J]”, Chinese Journal of Solid Mechanics, 2010, Vol. 31, pp. 275-280.

[14] Wang, Y.Q., Lin, C.C. and Shi, Y.J., "Experimental Study on the Temperature of Steel Members in Sunshine [J]”, Journal of Building Structures, 2010, Supplementary Issue Vol. 1, pp. 140-147. 
[15] Jin, X.F., Fan, F. and Shen, S.Z., "Effect of Non-uniform Temperature Field under Sunshine on the Structure Supporting the Reflector of a Large Radio Telescope-FAST [J]”, China Civil Engineering Journal, 2008, Vol. 41, No. 11, pp. 71-77.

[16] Brisn, K., Diefenderfer, Imad L. and Al-Qadi Stacey, D. Diefenderfer., "Model to Predict Pavement Temperature Profile: Development and Validation”, Journal of Transportation Engineering, 2006, Vol. 132, No. 2, pp. 162-167.

[17] Andrew, D. Chiasson, Cenk, Yavuzturk and Khaled, Ksaibati, "Linearized Approach for Predicting Thermal Stresses in Asphalt Pavements due to Environmental Conditions", Journal of Materials in Civil Engineering, 2008, Vol. 20, No. 2, pp. 118-127.

[18] Tong, M., Tham, L.G. and Au, F.T.K., ”Numerical Modeling for Temperature Distribution in Steel Bridges”, Computers and Structures, 2001, Vol. 79, No. 6, pp. 583-593.

[19] Kim, S.-H., Cho, K.-I., Won, J.-H. and Kim, J.-H., "A Study on Thermal Behavior of Curved Steel Box Girder Bridges Considering Solar Radiation”, Archives of Civil and Mechanical Engineering, 2009, Vol. 9, No. 3, pp: 59-76.

[20] Xu, Y.L., Chen, B., Ng, C.L., Wong, K.Y. and Chan, W.Y., "Monitoring Temperature Effect on a Long Suspension Bridge”, Structural Control and Health Monitoring, 2010, Vol. 17, No. 6, pp. 632-653.

[21] Jin, F., Chen, Z., Wang, J.T., Yang, J., "Practical Procedure for Predicting Non-uniform Temperature on the Exposed Face of Arch Dams”, Applied Thermal Engineering, 2010, Vol. 30, No. 14-15, pp. 2146-2156.

[22] Faye, C. McQuiston, Jerald, D. Parker and Jeffrey, D. Spitler, “Heating, Ventilating, and Air Conditioning Analysis and Design, USA, John Wiley and Sons, 2005. 